\title{
Interleukin 1-dependent Paracrine Granulopoiesis in Chronic Granulocytic Leukemia of the Juvenile Type
}

\author{
Grover C. Bagby, Jr.,"\# Charles A. Dinarello, Robert C. Neerhout," Derry Ridgway," and Elaine McCall* \\ *The Medical Research Service, Veterans Administration Medical Center, Portland, Oregon 97201; ${ }^{\ddagger}$ Division of Hematology and \\ Medical Oncology, The Department of Medicine and Division of Hematology/Oncology, Oregon Health Sciences University, Portland, \\ Oregon 97201; 'Division of Geographical Medicine and Infectious Diseases, Tufts New England Medical Center Hospital, Boston, \\ Massachusetts 02111; "Department of Pediatrics, Oregon Health Sciences University, Portland, Oregon 97201
}

\begin{abstract}
Marrow and peripheral blood cells from nine children with juvenile chronic granulocytic leukemia (JCGL) demonstrated intense (94 $\pm 16 \%$ maximum) spontaneous granulocyte/macrophage colony growth but cells from five children with the adult variety of CGL did not. This unusual pattern of colony growth depended upon a stimulatory protein(s) produced by mononuclear phagocytes. No GM-CSA activity was found in any chromatofocused fraction of JCGL monocyte-conditioned media but an activity that induced GM-CSA in umbilical vein endothelial cells was detected at pI 6.9-7.2. Moreover, the CSA-inducing monokine was neutralized by an anti-IL-1 antibody in vitro and, in the one case so tested, the same antibody also inhibited "spontaneous" colony growth. Therefore granulocyte/macrophage colony growth in JCGL is characteristically abnormal and distinguishes JCGL from the adult form of the disease. This abnormality depends upon the production, by mononuclear phagocytes, of IL-1 which, in turn, stimulates the release of high levels of colony stimulating activity by other cells. The high proliferative activity of CFU-GM we found in JCGL patients, and the high levels of GM-CSA found in their serum are compatible with the view that the in vitro abnormality reflects a similar abnormality in vivo.
\end{abstract}

\section{Introduction}

Chronic granulocytic leukemia in children consists of heterogeneous clinical subsets. In one variety, paradoxically called the "adult" type, children exhibit leukocytosis, largely neutrophilic, hepatosplenomegaly, and generally exhibit the Philadelphia $\left(\mathrm{Ph}^{\prime}\right)$ chromosomal translocation $(1,2)$. In a second type, "juvenile" chronic granulocytic leukemia (JCGL), ${ }^{1}$ children have variable degrees of organomegaly, often exhibit monocytosis and fetal characteristics of erythrocytes, and do not have cells with the classic $\mathrm{Ph}^{\prime}$ chromosome (1-4). We have, over the past 10 years, carried out a series of in vitro studies using bone

Address reprint requests to Dr. Bagby, Division of Hematology/Oncology, Oregon Health Sciences University, 3181 SW Sam Jackson Park Road, Portland, OR 97201. 1988.

Received for publication 15 June 1987 and in revised form 13 June

1. Abbreviations used in this paper: HPCM, human placental-conditioned medium; JCGL, juvenile chronic granulocyte leukemia; MCM, monocyte-conditioned media; MRA, monocyte-derived recruiting activity.

The Journal of Clinical Investigation, Inc.

Volume 82, October 1988, 1430-1436 marrow and blood cells from nine children with JCGL, five children with adult CGL, and more than 100 normal volunteers. We consistently found, in studies described here, that intense, usually maximal, granulocyte/macrophage colony growth occurred in cells from JCGL patients, cultured in assays to which no exogenous source of CSA had been added. This pattern was not seen in cultures of normal marrow cells, children with adult CGL or adults with chronic myelomonocytic leukemia. We subsequently carried out studies designed to determine whether the intense spontaneous colony growth seen in these children derived from autonomous clonal proliferation of the CFU-granulocyte/macrophage (GM) or whether it derived from the provision of growth factors by auxiliary cells that were not themselves capable of forming granulocyte/ macrophage colonies. Because monocytosis is a characteristic clinical feature in these children (3) and in view of the evidence supporting the regulatory role of such cells in hematopoiesis $(5-23)$, we focused our studies on potential abnormalities of monocyte/macrophage function in hematopoiesis.

\section{Methods}

Peripheral blood and bone marrow was obtained from paid, informed, and consenting normal adult volunteers. Bone marrow and blood samples from children were obtained initially as part of the diagnostic evaluation and subsequently to monitor the clinical course. The patients were classified as having the juvenile or adult forms of CGL based on clinical parameters previously published $(1,2)$.

CFU-GM assay. CFU-GM colony growth of low density (FicollHypaque, Pharmacia Fine Chemicals, Piscataway, NJ) bone marrow cells and fractions thereof were cultured in the presence and absence of colony-stimulating activity. Sources of CSA consisted of peripheral blood mononuclear leukocyte conditioned medium $(5,6)$ before 1979 and after 1979 of human placental conditioned medium $(24,25) .10^{5}$ cells were cultured in $1-\mathrm{ml}$ vol of $0.9 \%$ methylcellulose in alpha medium supplemented with $15 \%$ heat inactivated FCS. The methylcellulose was layered on an agar gel $(0.5 \% \mathrm{wt} / \mathrm{vol}$ in McCoy's $5 \mathrm{~A}$ medium) to which had been added $10 \% \mathrm{vol} / \mathrm{vol}$ of the undiluted human placental conditioned medium (HPCM) (8-10). Colonies (aggregates of more than 39 cells) were counted on days 7-9 of culture. Representative colonies were stained with Wright's/Giemsa and alpha-naphthyl butyrate esterase (Sigma Chemical Co., St. Louis, MO) for morphological analysis.

In some experiments, certain auxiliary cells were removed from the plated cell suspensions. $T$ lymphocytes were removed as previously described $(7,10)$ by exposing low density bone marrow cells to sheep erythrocytes followed by density centrifugation to remove the rosettepositive cells. Phagocytic cells were depleted from the low density bone marrow cell population and peripheral blood mononuclear leukocyte populations by an iron/magnet technique as previously described $(7,8$, 12). Adherent cells were depleted by passing mononuclear leukocytes and low density bone marrow cells over preincubated nylon fiber col- 
umns (Fenwal, Inc., Ashland, MA). T cell depleted, phagocyte-depleted, and adherent cell-depleted populations were resuspended in the original predepletion volume to avoid progenitor enrichment $(26,27)$. These depleted cell populations were then plated in CFU-GM assays as above.

$C F U$-GM suicide. Low density bone marrow cells from two children with JCGL and from two normal volunteers were, in an experiment based on a modification of the technique originally described by Millard and Okell (28), exposed to $50 \mu \mathrm{g} / \mathrm{ml}$ cytosine arabinoside (Upjohn Co., Kalamazoo, MI) in complete medium for 15, 30, 45, and 60 min. The cells were washed in medium thrice at $4^{\circ} \mathrm{C}$ then plated in CFU-GM assays with $20 \%$ leukocyte-conditioned medium in the agar underlayer.

Endothelial cell cultures. Confluent endothelial cell cultures in 8th-10th passage were prepared from human umbilical vein endothelial cells as previously described $(10,12,29)$. The cells exhibited the characteristic cobblestone appearance of endothelial cells and $98 \%$ of these cells contained Factor VIII-related antigen as determined by indirect immunofluorescence. Cell density ranged from 1 to $5 \times 10^{4}$ cells $/ \mathrm{cm}^{2}$.

Conditioned media. Monocyte-conditioned medium was prepared according to methods previously described $(8,10)$. Peripheral blood mononuclear phagocytes were prepared from heparinized peripheral blood on Ficoll-Hypaque. The low density cells were washed in RPMI 1640 twice and were adjusted to a concentration of $5 \times 10^{5} / \mathrm{ml}$. One ml of suspension was pipetted onto FCS-coated dishes $(8,10,12)$ and were incubated at $37^{\circ} \mathrm{C}$ for $1 \mathrm{~h}$. Nonadherent cells were removed and the adherent cells were cultured for a period of $3 \mathrm{~d}$ in RPMI 1640 with 5\% lactoferrin-depleted FCS. The adherent cells were $92 \pm 7 \%$ mononuclear phagocytes by nonspecific esterase staining. Human placental conditioned medium was prepared as described $(24,25)$.

T lymphocyte conditioned medium was prepared from 2-d cultures of T-cells isolated by lysis of the sheep erythrocytes in the rosette positive fraction $(26,27)$. T cells were cultured for $48 \mathrm{~h}$ in RPMI 1640 with $10 \%$ FCS.

$M R A$ and CSA assays. In the past we have defined monokines that induce CSA production by endothelial cells as monocyte-derived recruiting activity (MRA). MRA assays were carried out in three steps $(10,12) ;(a)$ peripheral blood mononuclear phagocytes were cultured to obtain monocyte-conditioned media (MCM) as above; (b) MCM was diluted serially and incubated for $3 \mathrm{~d}$ with endothelial cells in vitro; (c) colony-stimulating activity (CSA) titers were measured in the endothelial cell conditioned medium. All MCM samples were also assayed for CSA content.

CSA assays were carried out as described previously $(8,10,12)$. Low density bone marrow cells from normal volunteers were depleted of macrophages and $\mathrm{T}$ lymphocytes as above. $10^{5}$ cells were cultured in $1 \mathrm{ml} / \mathrm{vol}$ of $0.9 \%$ methylcellulose and alpha-medium supplemented with $15 \%$ heat-inactivated FCS. The methylcellulose was layered on agar gel $(0.5 \% \mathrm{wt} / \mathrm{vol}$ in McCoy's $5 \mathrm{~A}$ medium) to which had been added $10 \% \mathrm{vol} / \mathrm{vol}$ of the samples to be assayed. Each experiment included a positive CSA control of $10 \%$ human placental conditioned medium or peripheral blood leukocyte conditioned medium prepared as described above. Colonies were counted as above and representative colonies were plucked for morphological analysis. The CSA assays were performed using several dilutions of the endothelial cell conditioned medium. The CSA content of the sample was calculated from the linear portion of the dilution curve and one unit of CSA was defined as that amount resulting in the formation of one granulocyte macrophage colony $(12,16)$. Similarly, MRA content was calculated from the linear portion of the MRA dilution curve. We have defined one unit of MRA as that amount stimulating the formation of one unit of CSA (12).

The sensitivity of colony forming units was assessed by culturing T-depleted nonadherent low density marrow cells from five normal volunteers and seven JCGL patients in CFU-GM assays with leukocyte conditioned medium.
CSA was measured in serum from three patients with drug-induced agranulocytosis (two procainamide, one diphenylhydantoin, two patients with JCGL, (the same two whose CFU-GM were challenged with cytosine arabinoside), five umbilical cord blood samples and five normal adults by adding three separate dilutions of sera to agar underlayers, then overlaying them with nonadherent low density marrow cells in $0.8 \%$ agar for $7 \mathrm{~d}$. Sera were stored at $-20^{\circ} \mathrm{C}$ before bioassay. CSA is expressed as units per milliliter as described above.

Chromatofocusing. $100 \mathrm{ml}$ of fresh MCM was concentrated to $8 \mathrm{ml}$ by dialysis at room temperature in spectrapor 3 dialysis tubing $(3,500$ D cut-off) against $25 \% \mathrm{wt} / \mathrm{vol}$ polyethylene glycol MW, 8000 (Fisher Scientific, Santa Clara, CA). The concentrated sample was then further dialyzed for $24 \mathrm{~h}$ against 0.025 imidazole buffer ( $\mathrm{pH} 7.4$ at $\left.4^{\circ} \mathrm{C}\right)$. The concentrated dialyzed sample of MCM was applied to a poly buffer exchanger column (Pharmacia Fine Chemicals) and eluted with poly buffer 74, diluted 1:8 with water and adjusted to $\mathrm{pH}$ 4.0. Fractions of 3 $\mathrm{ml}$ were collected at $0.5 \mathrm{ml} / \mathrm{min}$ for $2-3 \mathrm{~h}$. The $\mathrm{pH}$ of each fraction was measured and the fractions filtered through $0.22 \mu \mathrm{m}$ low binding filters (Millipore Corp., Bedford, MA). The eluted fractions were tested in MRA assays in CSA assays. The pattern of elution of monocyte-conditioned media were compared to the patterns of elution of MRA and CSA from human placental conditioned medium which contains both CSA and MRA (25).

IL-1 assays. IL-1 assays were performed using a cell line (LBRM33-1 A5) that produces IL-2 in response to IL-1 and phytohemagglutinin-M (PHA-M), according to techniques previously described (29). Briefly, $5 \times 10^{5}$ cells $/ \mathrm{ml}$ were cultured in medium with or without PHA (0.1\%), or with control samples with and without PHA. Supernatants from these first cultures were transferred to duplicate microtiter plates to which $4 \times 10^{4} / \mathrm{ml}$ CTLL-2 cells were added. CTLL cells in microculture wells were incubated for an additional $20 \mathrm{~h}$ followed by a 4-h pulse with $0.5 \mathrm{mCi}$ of $\left[{ }^{3} \mathrm{H}\right]$ thymidine (sp act $6.7 \mathrm{Ci} / \mathrm{mmol}$; New England Nuclear, Boston, MA). Lymphocyte activation factor (LAF) activity was expressed as cpm incorporated into the harvested cells.

Purified anti-IL-1 rabbit immunoglobulin. The anti-IL-1 immunoglobulin used in these studies was prepared from rabbits immunized with human native IL-1 as previously described $(13,30)$. Because the $0.5 \%$ final concentration of the antibody is optimally inhibitory in the IL-1 assay (13), all subsequent antibody neutralization studies were performed using this dilution. Samples of MCM from three children with JCGL were treated with the antibody as above and then utilized in MRA and CSA assays. Two dilutions of antibody-treated MCM (1:1, 1:9) were analyzed in MRA assays as described above. Control studies indicated that the antibody alone had no effect on endothelial cell viability, on CSA released by endothelial cells, or on colony growth $(13,16)$

\section{Results}

Because of the variability from lot to lot of the conditioned media used as sources of CSA in our GM colony growth assays, granulocyte colony growth is expressed as the percentage of maximum growth. 13 separate lots of conditioned media were utilized for studies in 14 children. We obtained two representative normal clonogenic assay results from all but one of these conditioned media. Thus, the 25 normal volunteers included in Fig. 1 were individuals studied with 13 separate samples of stimulatory conditioned media. Nonspecific esterase positive (monocyte/macrophage) cells constituted $26-48 \%$ of low density bone marrow cells in JCGL patients, $15-26 \%$ in normal volunteers, and $12-32 \%$ in CGL patients. As shown in Fig. 1, "spontaneous" colony growth (i.e., that which occurred in the absence of exogenous granulopoietic factors) by bone marrow cells of the JCGL group was substantially higher than spontaneous colony growth in the 


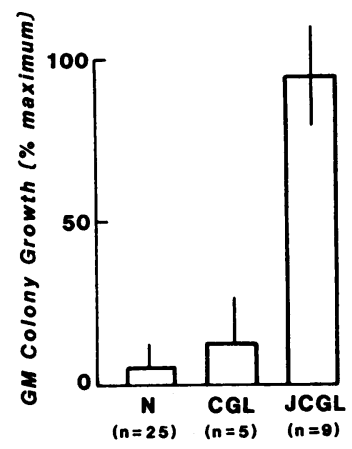

Figure 1. Spontaneous colony growth in chronic granulocytic leukemia of childhood. Colony growth that occurred in the absence of exogenous CSA is expressed on the $y$ axis as percent maximum where $100 \%$ represented the maximal colony growth induced by exogenous CSF in each case. Bars and vertical lines represent means and standard deviations of the groups indicated. $N$, normal volunteers; CGL, chronic granulocytic leukemia of the adult type, JCGL, CGL of the juvenile type. Maximum number of colonies (mean/10 $\pm \mathrm{SD}$, range) in each group were: $N=136 \pm 73$, range 50-315; CGL, $360 \pm 164$, range 84-560; JCGL, 253 \pm 128 , range 120-520.

adult CGL and normal volunteer groups $(P<0.001)$. Additional clonogenic assays were performed using fractionated bone marrow cells in seven children with JCGL to determine whether the spontaneous growth pattern was reflective of an activity of auxiliary cells or of an intrinsic clonogenic capacity of the colony-forming cells in these children. In two cases only adherent cells were depleted, a manuever that reduced spontaneous colony growth by 85 and $97 \%$, respectively (not shown). In one case only $\mathrm{T}$ lymphocytes were removed and spontaneous colony growth declined by only $8 \%$ (not shown). In four of these seven, both $T$ lymphocytes and adherent or phagocytic cells were depleted. In two of these four patients (Fig. $2 \mathrm{~A}$ ) only the removal of adherent cells was associated with a substantial reduction in spontaneous colony growth. No significant reduction in the total number of CFU-GM occurred as a result of any depletion step. In two patients the removal of T lymphocytes, adherent cells, and phagocytes or combinations of those reduced spontaneous colony growth substantially (Fig. 2 $B)$. The differences between these two groups of two patients cannot be explained at this time but may reflect variations in the degree of $\mathrm{T}$ cell depletion. In our hands, $\mathrm{E}$ rosette-depleted
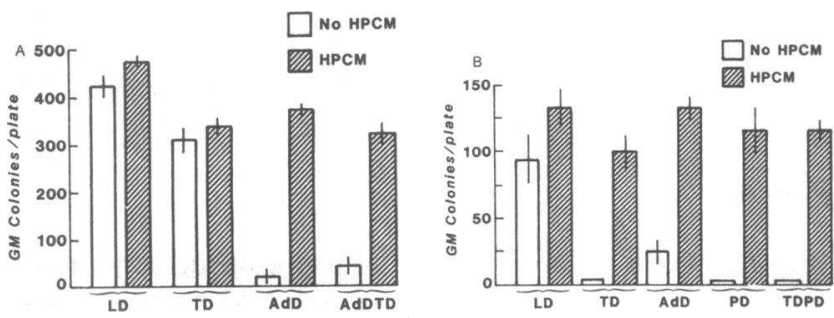

Figure 2. CFU-GM colony growth of fractionated bone marrow cells from four patients with JCGL. Bars and vertical lines represents means \pm SD. Low density cells were plated at $2 \times 10^{5} / \mathrm{ml}$. (A) Colony growth using bone marrow target cells from two patients with JCGL and one single source of CSA (human placental conditioned medium). Low density bone marrow cells (LD) $\left(2 \times 10^{5} /\right.$ plate $)$ and low density cells from which $T$ lymphocytes had been depleted (TD) both had high levels of spontaneous colony growth. The removal of adherent cells (AdD) or adherent cells and T cells (AdDTD) abrogated substantially spontaneous colony growth in these two patients. (B) As shown above, low density cells cultured in the absence of CSA (open bars) had substantial spontaneous colony growth but in these two patients removal of $T$ lymphocytes, adherent cells, phagocytes (PD) and both T lymphocytes and phagocytes (TD-PD) all substantially abrogated spontaneous colony growth. cells contain from 1-11\% T lymphocytes. We did not, however, measure residual $\mathrm{T}$ cell content in these four patients. In the remaining three patients only adherent (two cases) or phagocytic cells (one case) were depleted and in each case spontaneous colony growth declined by more than $70 \%$.

To determine whether the observed abnormality of spontaneous colony growth reflected hypersensitivity of CFU-GM to growth factors produced by auxiliary cells we compared, in seven patients and five normal volunteers, dose (CSA) response (colony growth) curves. As shown in Fig. 3, no differences were found when normal and leukemic CFU-GM were stimulated by mononuclear leukocyte conditioned medium.

Conditioned media from cultures of either $\mathrm{T}$ lymphocytes or mononuclear phagocytes were obtained from the two patients represented in Fig. $2 B$ to determine which of the cell populations produced hematopoietic growth factors. So that we could distinguish between the production of direct acting growth factors (CSA) and factors produced by these cells that augmented the production of CSA by other cells (MRA), we added these conditioned media not only to low density bone marrow cells but to low density bone marrow cells that had been depleted of $\mathrm{T}$ lymphocytes, phagocytes, and adherent cells. As shown in Fig. 4, three day cultures of $T$ lymphocytes failed to produce any colony stimulating activity, whereas cultures of mononuclear phagocytes induced colony growth but more substantially when added to low density bone marrow cells than with assayed against auxiliary depleted bone marrow cells. These observations were compatible with the point of view that even in the cultures of the two children in whom $T$ lymphocyte depletion suppressed colony growth, the mononuclear phagocytes were the auxiliary cells of primary importance. Because the soluble activity in monocyte-conditioned medium was trypsin sensitive (data not shown) we carried out studies designed to biophysically characterize the factor in monocyte conditioned medium which resulted in an enhancement of colony growth in vitro.

Complex media containing both MRA (IL-1) and CSA pose problems for interpretation of bioassays. These activities can be separated biophysically in certain conditioned media by using chromatofocusing $(13,25)$. Accordingly, we chose to analyze monocyte-conditioned medium using chromatofocusing techniques. As shown in Fig. $5 \mathrm{~A}$, concentrated conditioned media from cultures of monocytes derived from a child with JCGL contained MRA, which eluted at a pH of 6.4 to 7.0, but contained no colony stimulating activity. Human placen-

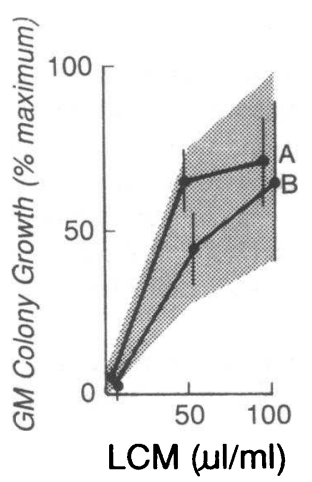

Figure 3. CSA responsiveness in nonadherent marrow cells from seven patients with JCGL and in five normal volunteers. Because of variable plating efficiencies, colony growth is expressed as \% maximum. Bars and vertical lines represent mean values $\pm S D$. Curve $B$ represents the results of cultures of normal cells $(n=5)$, curve A of JCGL cells ( $n$ $=7$ ). In each experiment, $1-2 \times 10^{5}$ cells were cultured in semisolid agar or methylcellulose layered upon an agar underlayer containing various concentrations of leukocyte conditioned medium. The shaded area represents the range of normal values. 


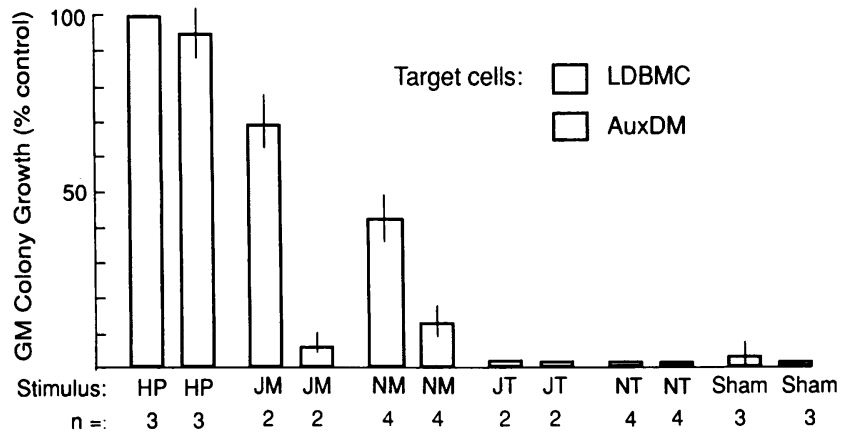

Figure 4. The granulopoietic activity of leukocyte conditioned medium from children with JCGL is a non-CSA monokine. Bars and vertical lines represent means \pm SD of granulocyte colonies induced by culturing normal bone marrow cells with $10 \%$ conditioned medium in double layer agar cultures. The cellular source of the conditioned medium is designated by both low density bone marrow cells and low density bone marrow cells from which $\mathrm{T}$ lymphocytes, phagocytes, and adherent cells had been depleted (AuxDM) were utilized. Supernatant media were derived from cultures of peripheral blood cells from two patients with juvenile chronic granulocytic leukemia $(J)$ and five normal volunteers $(N)$. T lymphocyte conditioned media ( $J T$ and $N T$ ) failed to induce colony formation (the T lymphocytes were not stimulated by mitogens or growth factors). Supernatants of monocyte cultures ( $J M$ and $N M$ ) induced substantial colony formation but only in cultures of LDBCM, not in auxiliary cell depleted marrow. Human placental conditioned medium $(H P)$ induced colony growth with both types of bone marrow cells. Controls labeled "sham" represented 3-d cultures of medium alone that were then added to bone marrow cells as above.

tal-conditioned medium (HPCM) chromatofocused as a positive control (25), gave not only pI 7 MRA fractions but pI 5 MRA and a CSA peak at pI 5 (Fig. 5 B).

Recently we have shown that the MRA at pI 7.0 is IL-1 beta (13). Accordingly, we prepared monocyte-conditioned media from three children with JCGL and treated these media in neutralization experiments with the IL-1 antibody (13). Again none of these three samples of MCM contained GMCSA. However, each contained an activity which stimulated the release, by endothelial cells of CSA. As shown in Fig. 6, treatment of two dilutions of these monocyte conditioned media with the neutralizing antibody completely abrogated the activity of these samples. Antibody added to HPCM tested against auxiliary depleted cells did not substantially reduce the CSA activity of HPCM (not shown). Accordingly, as we have described in the past (13), the inhibitory effect of the antibody was specifically on the monocyte-derived CSA-recruiting activity. In one case the anti-IL-1 immunoglobulin was added to CFU-GM assays of JCGL marrow. The immunoglobulin markedly inhibited spontaneous colony growth (Table I), but failed to inhibit HPCM-induced colony growth.

If high activity IL-1-dependent CSA production seen in vitro reflects an in vivo abnormality, one would expect to find high levels of CSA either in serum or bone marrow samples, and to also observe that freshly obtained CFU-GM from JCGL patients, having been chronically exposed to such high levels of CSA, might be more actively proliferative than normal CFU-GM. Results from serum CSA bioassays (Table II) and CFU-GM suicide studies (Fig. 7) on samples from two patients with JCGL and two normal volunteers that did, indeed, show high serum CSA and high level CFU-GM proliferative activity
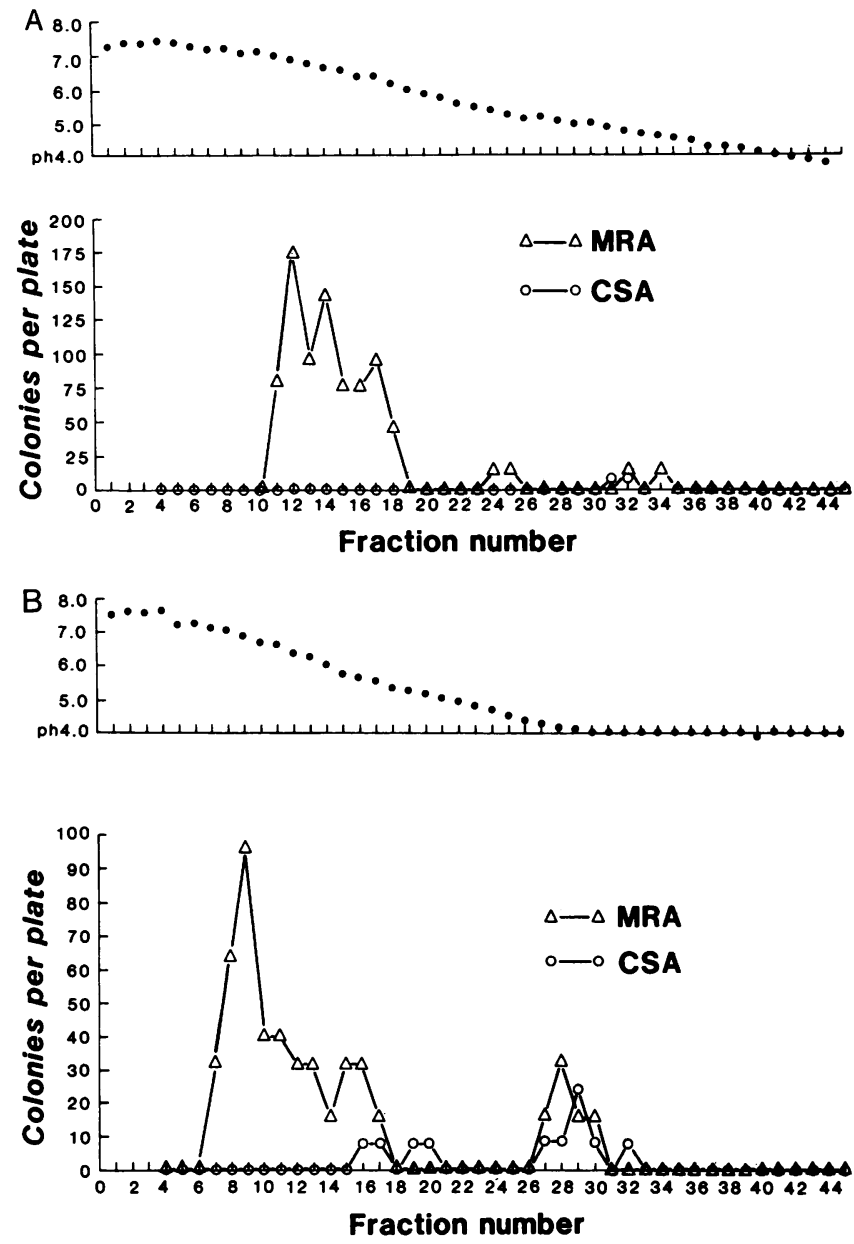

Figure 5. Chromatofocusing of conditioned medium. (A) 12-fold concentrated MCM from one patient with JCGL was dialyzed against 0.025 imidazole buffer $\left(\mathrm{pH} 7.4,4^{\circ} \mathrm{C}\right)$ and was applied to a poly-buffer exchanger column. Fractions of $3 \mathrm{ml}$ each were collected and analyzed for both MRA (triangles) and CSA (circles) content. In this representative experiment the upper curve marks the $\mathrm{pH}$ of the eluted fraction. Minimal CSA was detected between 7.5 and 5.0. IL-1 beta eluted in the major peak around pH 7.0. (B) The chromatofocusing profile of human placental conditioned medium; both MRA and CSA were present. The MRA eluting at pI 7 is IL-1 beta, the pI 5 material is IL-1 alpha $(13,38)$.
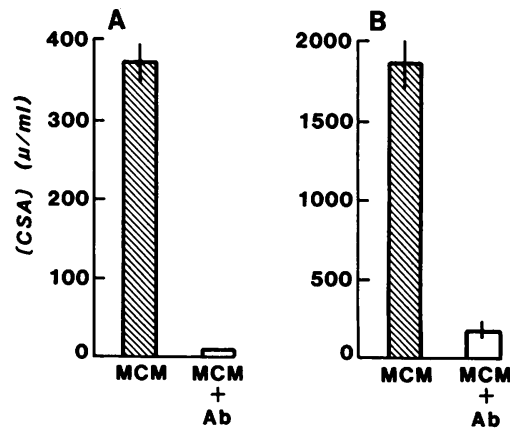

Figure 6. Neutralization of MRA with anti-IL-1 antibody. Using the optimal dose $(0.5 \%$ dilution) of antibody, we exposed monocyte-conditioned medium from three patients with JCGL leukemia to the IL-1 antibody for $18 \mathrm{~h}$ at $4^{\circ} \mathrm{C}$. The treated monocyte conditioned media was then assayed

for MRA and CSA content $(\mathrm{U} / \mathrm{ml})$ in a $2 \%(A)$ and $10 \%(B)$ final dilution of MCM. The MRA content of MCM from these patients declined markedly after treatment with the IL-1 antibody. In control studies the antibody did not inhibit colony growth of normal bone marrow cells stimulated with HPCM. Treatment of endothelial cells with the antibody neither enhanced CSA production nor decreased endothelial cell viability in 3-d cultures. 
Table I. Juvenile Chronic Granulocytic Leukemia: The Effect of Anti-IL-1 Immunoglobulin on Spontaneous and Induced CFU-GM Growth

\begin{tabular}{ccc}
\hline HPCM & $\begin{array}{c}\text { Anti-IL-1 } \\
\text { immunoglobulin }\end{array}$ & $\begin{array}{c}\text { Colonies } / 10^{5} \text { low density } \\
\text { marrow cells }( \pm \text { SD) }\end{array}$ \\
\hline 0 & 0 & $154 \pm 8$ \\
0 & + & $64 \pm 14$ \\
$10 \%$ & 0 & $184 \pm 6$ \\
$10 \%$ & + & $192 \pm 14$
\end{tabular}

$1 / 200$ dilution of rabbit anti-IL-1 immunoglobulin added to marrow cells in methylcellulose.

(relative not only to our controls, but to the control studies of others who have utilized cytosine arabinoside in this way [28, 31]) support this view.

\section{Discussion}

When normal unfractionated low density bone marrow cells are used in colony growth assays, spontaneous granulocyte/ macrophage colony growth is commonily observed because low levels of GM-CSA are produced by normal auxiliary marrow cells (7). The intensity of colony growth (Fig. 1) seen in cultured marrow cells from children with JCGL is unique and, in our series, serves to distinguish it from the patterns of GMcolony growth not only of normal marrow, but of marrow cells from children with adult-type (Philadelphia chromosome positive) CGL as well. This pattern of growth could, theoretically arise as a consequence of an intrinsic proliferative autonomy of the progenitors themselves, in which no growth factors would be required at all, or might result from the release of growth factors by auxiliary cells. Because spontaneous colony growth decreased almost completely after depletion of auxiliary cell populations in all of the seven children so tested (Fig. 2) the release of CSA by auxiliary cells obviously accounted for the phenomenon.

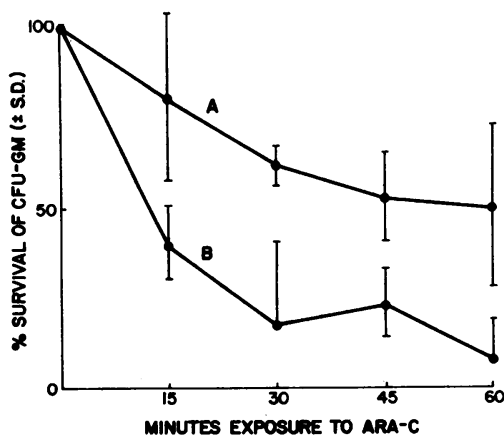

Figure 7. Survival of CFU-GM after exposure to $50 \mu \mathrm{g} / \mathrm{ml}$ cytosine arabinoside for from 15 to $60 \mathrm{~min}$. Low density bone marrow cells from two patients with JCGL $(B)$ and two normal volunteers were exposed to cytosine arabinoside, were washed after various timed durations of exposure and were plated in CFU-GM assays over underlayers containing $10 \%$ peripheral blood leukocyte conditioned medium. Bars and vertical lines represent mean percent survival \pm SD where at each time point, $100 \%$ represents granulocyte macrophage colony growth of cells cultured for the same periods of time in the absence of cytosine arabinoside. The survival of JCGL progenitors after cytosine arabinoside was significantly less than survival of normal CFU-GM $(P<0.005$, analysis of variance).
Table II. [GM-CSA] (U/ml $S$ SD) in Serum Samples

$\left.\begin{array}{lcc}\hline \multicolumn{1}{c}{\text { Source }} & n & \text { [GM-CSA] } \\ \hline \text { Neutropenia } & 3 & 2,260 \pm 420 \\ \text { Umbilical cord } & 5 & 400 \pm 160 \\ \text { JCGL } & 2 & 920 \pm 400 \\ \text { Normal adult } & 5 & 120 \pm 80\end{array}\right\} P<0.05^{*}$

* Analysis of variance.

The observed spontaneous colony growth might derive from; (a) the production of abnormal amounts of CSA by auxiliary cells, $(b)$ the production of mutant or unusual CSA molecules with high specific activity, $(c)$ the absence in the cultures (and perhaps in the patients of a feedback mechanism regulating CSA production or $(d)$ an increase in the sensitivity of CFU-GM to otherwise normal CSA. CSA dose-response curves were defined using cells from seven children (Fig. 3) using serial dilutions of leukocyte conditioned medium, and although the results must be repeated using recombinant growth factors, we found no evidence for an increase in progenitor sensitivity.

We sought next to quantitate CSA produced by monocyte/macrophages and were frustrated by our inability to detect much CSA at all in the monocyte supernatants from either normal donors or children with JCGL when the assays were performed, as CSA assays must be, using auxiliary cell-depleted marrow. At this time, based on related studies in our laboratory, we had begun to revise our notion of the mechanism by which monocytes and macrophages stimulate colony growth in vitro $(7,8,10,11)$.

The role of mononuclear phagocytes as regulators or hematopoiesis has long been recognized. Initially, unstimulated monocytes themselves were thought to provide a factor CSA, which stimulated the clonal proliferation of granulocyte macrophage colony-forming units, $\mathrm{CFU-GMs}(5,6)$. While monocytes themselves can be induced to release CSA $(22,23)$, recent studies from a number of laboratories, including our own, have demonstrated that monocytes also provoke accessory cells to release hematopoietic growth factors, including granulocyte colony stimulating factor (G-CSF) and granulocyte macrophage colony stimulating factor (GM-CSF), by releasing IL-1 and tumor necrosis factor alpha (12-14, 17, 18, 20, 21). Therefore, while the pattern of spontaneous colony growth, by definition, depended upon the production of CSA by auxiliary cells in the JCGL bone marrow samples, we did not know whether the production of CSA was autonomous or was induced by a monokine. Therefore, we tested the hypothesis that the role of monocytes in the aberrant pattern of spontaneous colony growth depended on their release of IL-1 that induced CSF gene expression by other hematopoietic cells.

That supernatants of monocytes very actively stimulated colony growth only when auxiliary cells were present in the cultured target bone marrow, was compatible with this hypothesis. While all seven patients tested exhibited adherent cell-dependent and T lymphocyte-dependent spontaneous colony growth, cells from two of the patients exhibited both adherent cell dependent and $T$ lymphocyte dependent spontaneous colony growth (Fig. $2 \mathrm{~B}$ ) compatible with the view that monocytes and $T$ cells interacted to produce large amounts of 
colony stimulating activity (7). This idea was also supported by chromatofocusing studies (Fig. 5) which indicated that the monocyte conditioned media from JCGL patients did not contain CSA but did contain IL-1 activity. Antibody neutralization studies demonstrated the presence of IL-1 beta (Fig. 6). In one case, the inhibitory effect of the anti-IL-1 antibody on spontaneous colony growth (Table I) was most compatible with the view that CSA production by unfractionated bone marrow cells was "driven" by native IL-1 beta.

Although recent studies have supported the notion that certain neoplastic cells produce and respond to their own growth factors (32), in vitro evidence for such an "autocrine" mechanism in the myeloid leukemias has been lacking. It is generally acknowledged that leukemic cells from patients with either acute or chronic myeloid leukemias, with few exceptions (33), do not generally exhibit clonal growth in the absence of exogenous CSA $(34,35)$. In contrast, spontaneous granulocyte/macrophage colony growth in juvenile chronic granulocytic leukemia seems to be the rule (36). We have learned that this pattern of colony growth is explained neither by progenitor autonomy nor autonomous CSA production. The mononuclear phagocyte, through its release of IL-1, indirectly induces granulocyte/macrophage colony growth by a paracrine mechanism effecting the release of CSA from bystander auxiliary cells. Because this same intercellular network phenomenon, or something closely resembling it, occurs, albeit with less intensity, in normal marrow cell cultures $(7,8$, 13) (Fig. 4), we do not yet know the exact mechanism by which progenitor growth occurs in marrow cells from these children.

Clearly, prominent monocytosis is a characteristic of JCGL (3). In fact, the minimal increase in the mean fraction of monocytes plated in the JCGL group may have contributed to the abnormality. In view of recent reports that monocytes themselves are capable of releasing GM-CSA in response to IL-1 (23), theoretically, the abnormality so characteristic of in vitro clonal growth of granulocyte progenitors from patients with JCGL might be explained in a number of ways. Inappropriate production of high levels of IL-1, the high-level sensitivity to IL-1 of CSA producing cells, absence of factors that repress IL-1 gene expression, or qualitative abnormalities of the IL-1 molecule leading to high specific activity, each might serve to explain our observations. Nor can we yet rule out the possibility that CSFs with uniquely high specific activity are induced by IL-1 in this disease. While we and others have ascertained that IL-1 induces expression of G- and GM-CSF in normal stromal cells $(14,20)$, the nature of CSA induced in JCGL patients is unknown. The distribution of monocyte $(25-40 \%)$ and neutrophil colonies $(60-75 \%)$ in each patients is compatible with the notion that the JCGL monocytes stimulated the release of GM-CSF $(36,37)$. Nevertheless we cannot rule out the possibilities that both G-CSF and M-CSF are produced or that multiple CSFs are released $(16,17,35,38-40)$.

Our studies to date have been strictly in vitro observations but two observations on freshly obtained marrow and serum suggest that the production of high levels of growth factors existed in vivo. First, as shown in Fig. 7, the proliferative activity of CFU-GM from JCGL patients was abnormally high. This implies that the CFU-GM either proliferate autonomously (incompatible with colony growth results in Fig. 2) or are "driven" (in vivo) to proliferate by CSFs. Compatible with the latter view are observations on serum CSA levels that were abnormally high in JCGL patients (Table II). Until reliable assays are developed for the detection of IL-1 in human body fluids and serum samples from such patients, studies which must necessarily take into account technical difficulties imposed by the presence of inhibitors of IL-1 (41), the relevance of even these observations to the pathophysiology of this disease will be uncertain. Nonetheless, that intense spontaneous colony growth was found to be universal in the children with juvenile chronic granulocytic leukemia, that it derived from the production of IL-1 by mononuclear phagocytes, that no marrow cell, including monocytes, independently produced detectable CSA, that the CFU-GM in these patients do not form colonies autonomously but are highly proliferative when freshly obtained, and that serum CSA titers are abnormally high, at least using bioassays, suggest that such studies are warranted. We propose that IL-1 dependent production of high activity or uniquely synergistic granulopoietic colony stimulating factors may represent an important mechanism by which granulopoietic hyperplasia develops in children with juvenile chronic granulocytic leukemia.

\section{Acknowledgments}

Supported by grants from the National Cancer Institute (DHHS, CA-36306), the Veterans Administration, and the National Institutes of Health (DHHS AI-15614).

\section{References}

1. Mays, J. A., R. C. Neerhout, G. C. Bagby, and R. D. Koler. 1980. Juvenile chronic granulocytic leukemia. Am. J. Dis. Child. 134:654658.

2. Barak, Y., S. Levin, R. Vogle, I. J. Cohen, B. Wallach, E. Nir, and R. Zaizov. 1981. Juvenile and adult types of chronic granulocytic leukemia of childhood: growth patterns and characteristics of granulocyte-macrophage colony forming cells. Am. J. Hematol. 10:269-275.

3. Altman, A. J., C. G. Palmer, and R. L. Baehner. 1974. Juvenile "chronic granulocytic" leukemia: a panmyelopathy with prominent monocytic involvement and circulating monocyte colony forming cells. Blood. 43:341-347.

4. Brodeur, G. J., L. W. Dow, and D. L. Williams. 1979. Cytogenetic features of juvenile chronic myelogenous leukemia. Blood. 53:812-819.

5. Golde, D. W., and M. J. Cline. 1972. Identification of colonystimulating cells in human peripheral blood. J. Clin. Invest. 51:29812983.

6. Chervenick, P. A., and A. F. LoBuglio. 1972. Human blood monocytes, stimulators of granulocyte and mononuclear colony formation in vitro. Science (Wash. DC). 178:164-166.

7. Bagby, G. C., V. D. Rigas, R. M. Bennett, A. A. Vandenbark, and H. S. Garewal. 1981. Interaction of lactoferrin, monocytes, and T-lymphocyte subsets in the regulation of steady-state granulopoiesis in vitro. J. Clin. Invest. 68:56-63.

8. Bagby, G. C., E. McCall, and D. L. Layman. 1983. Regulation of colony stimulating activity production. Interactions of fibroblasts, mononuclear phagocytes and lactoferrin. J. Clin. Invest. 71:340-344.

9. Gerson, S. L., H. M. Friedman, and D. B. Cines. 1985. Viral infection of vascular endothelial cells alters production of colony-stimulating activity. J. Clin. Invest. 76:1382-1390.

10. Bagby, G. C., E. McCall, K. A. Bergstrom, and D. Burger. 1983. A monokine regulates colony-stimulating activity production by vascular endothelial cells. Blood. 62:663-668.

11. Broudy, V., K. Zuckerman, S. Jetmalani, J. H. Fitchen, and G. C. Bagby. 1986. Monocytes stimulate fibroblastoid marrow stromal cells to produce multilineage hematopoietic growth factors. Blood. 68:530-534. 
12. McCall, E., and G. C. Bagby. 1985. Monocyte-derived recruiting activity. Kinetics of production and effects of endotoxin. Blood. 65:689-695.

13. Bagby, G. C., C. A. Dinarello, P. Wallace, C. Wagner, S. Hefeneider, and E. McCall. 1986. Interleukin-1 stimulates granulocyte macrophage colony stimulating activity release by vascular endothelial cells. J. Clin. Invest. 78:1316-1323.

14. Sieff, C. A., S. Tsai, and D. V. Faller. 1987. Interleukin-1 induces cultured human endothelial cell production of granulocyte macrophage colony-stimulating factor. J. Clin. Invest. 79:48-51.

15. Zucali, J. R., C. A. Dinarello, D. J. Oblon, M. A. Gross, L. Anderson, and R. S. Weiner. 1986. Interleukin-1 stimulates fibroblasts to produce granulocyte macrophage colony stimulating activity and prostaglandin $\mathrm{E}_{2}$. J. Clin. Invest 77:1857-1863.

16. Segal, G. M., E. McCall, T. Stueve, and G. C. Bagby, Jr. 1987. Interleukin-1 stimulates endothelial cells to release multilineage human colony-stimulating activity. J. Immunol. 138:1772-1778.

17. Bagby, G. C. 1987. Production of multilineage growth factors by hematopoietic stromal cells: an intercellular regulatory network involving mononuclear phagocytes and interleukin-1. Blood Cells. 13:147-159.

18. Broudy, V. C., K. Kaushansky, G. M. Segal, J. M. Harlan, and J. W. Adamson. 1986. Tumor necrosis factor type alpha stimulates human endothelial cells to produce granulocyte/macrophage colony stimulating factor. Proc. Natl. Acad. Sci. USA. 83:7467-7471.

19. Zuckerman, K. S., G. C. Bagby, E. McCall, B. Sparks, J. Wells, and V. Patel. 1985. A monokine stimulates production of human erythroid burst promoting activity by endothelial cells in vitro. J. Clin. Invest. 75:722-725.

20. Zsebo, K. M., V. Yuschenkoff, S. Schulter, D. Chong, E. McCall, C. A. Dinarello, B. Altrock, and G. C. Bagby, Jr. 1988. Vascular endothelial cells and granulopoiesis. Interleukin-1 stimulates release of G-CSF and GM-CSF. Blood. 71:99-103.

21. Munker, R. J., J. Gasson, M. Ogawa, and H. P. Koeffler. 1986. Recombinant human TNF induces production of granulocyte-monocyte colony stimulating factor. Nature (Lond.). 323:79-82.

22. Rambaldi, A., D. C. Young, J. D. Griffin. 1987. Expression of the M-CSF (CSF-1) gene by human monocytes. Blood. 69:1409-1413.

23. Fibbe, W. F., J. vanDamme, H. M. Goselink, A. Billiau, P. J. Voogt, and J. H. F. Falkenberg. 1987. Purified human interleukin-1 induces GM-CSA release by mononuclear phagocytes. Blood. 68:1316-1321.

24. Schlunk, T., and M. Schleyer. 1980. The influence of culture conditions on the production of colony stimulating activity by human placenta. Exp. Hematol. 8:179-184.

25. McCall, E., R. K. Rathbun, M. Riscoe, B. Wilkinson, and G. C. Bagby. 1986. Human placental conditioned medium contains monocyte-derived recruiting activity (MRA). Exp. Hematol. 14:789-792.

26. Bagby, G. C. 1981. T-lymphocytes which inhibit granulopoiesis in two neutropenic patients are of the cytotoxic suppressor $\left(\mathrm{OKT}^{+}\right.$, $\mathrm{OKT}^{+}$) subset. J. Clin. Invest. 68:1597-1600.

27. Bagby, G. C., J. H. Lawrence, and R. C. Neerhout. 1983 Autoimmune granulopoietic failure identification of T-lymphocytemediated inhibition of granulopoiesis and prednisone responsiveness using in vitro techniques. N. Engl. J. Med. 309:1073-1078.

28. Millard, R. E., and S. F. Okell. 1975. The effect of cytosine arabinoside in vitro on agar colony forming cells and spleen colony forming cells of C57BL mouse bone marrow. Cell Tissue Kinet. 8:33-40.

29. Wagner, C. R., R. M. Vetto, and D. Burger. 1985. Expression of I-region-associated antigen (Ia) and interleukin-1 by subcultured human endothelial cells. Cell. Immunol. 93:91-104.

30. Dinarello, C. A., H. A. Bernheim, J. G. Cannon, G. Lopreste, S. J. C. Warner, A. C. Webb, and P. E. Auron. 1985. Purified, ${ }^{35}$ SMET, ${ }^{3} \mathrm{H}$-LEU-labelled human monocyte interleukin-1 (IL-1) with endogenous pyrogen activity. Br. J. Rheumatol. 24:(Suppl.)59-64.

31. Dresch, C., N. El-Kebir, J. Metral, and A. Karsdorf. 1983. Cytosine arabinoside as a suicide agent for human colony forming cells. Exp. Hematol. 11:187-192.

32. Sporn, M. B., and A. B. Roberts. 1985. Autocrine growth factors and cancer. Nature (Lond.). 313:745-747.

33. Young, D. C., and J. D. Griffin. 1986. Autocrine secretion of GM-CSF in acute myeloblastic leukemia. Blood. 68:1178-1181.

34. Metcalf, D., N. A. Nicola, and C. G. Begley. 1984. The colony stimulating factors and myeloid leukemia. In Leukemia: Recent Advances in Biology and Treatment. R. P. Gale and D. W. Golde, editors. Alan R. Liss, New York. 267-276.

35. Metcalf, D. 1986. The molecular biology and functions of the granulocyte macrophage colony stimulating factors. Blood. 67:257267.

36. Altman, A. J., and R. L. Baehner. 1975. In vitro colony forming characteristics of chronic granulocytic leukemia in childhood. J. Pediatr. 86:221-224.

37. Metcalf, D., C. G. Begley, and G. R. Johnson. 1986. Biologic properties in vitro of a recombinant human granulocyte macrophage colony stimulating factor. Blood. 67:37-45.

38. Broudy, V. C., K. Kaushansky, J. M. Harlan, and J. W. Adamson. 1987. Interleukin-1 stimulates human endothelial cells to produce granulocyte-macrophage colony-stimulating factor and granulocyte colony-stimulating factor. J. Immunol. 139:464-468.

39. Tomonaga, M., D. W. Golde, and J. C. Gasson. 1986. Biosynthetic (recombinant) human granulocyte macrophage colony stimulating factor: effect on normal bone marrow and leukemia cell lines. Blood. 67:31-36.

40. Kawasaki, E. X., M. B. Ladner, and A. M. Wang. 1985. Molecular cloning of a complementary DNA encoding human macrophagespecific colony stimulating factor (CSF-1). Science (Wash. DC) 230:291-296.

41. Dinarello, C. A. 1984. Interleukin-1. Rev. Infect. Dis. 6:51-95. 